\title{
Role of Psychoeducation on Self- Management of Type 1 Diabetes in Adolescents - A Review
}

\author{
Sanjana Malhotra ${ }^{1 *}$, Sherin P. Antony ${ }^{2}$
}

\section{ABSTRACT}

The efficacy of Psychoeducation for adolescents with type 1 diabetes mellitus has long been debated among mental health professionals. Psychoeducation is an effective intervention which aids in managing the mental health concerns of the adolescents along with the parameters of their illness such as insulin regimen, dietary and exercise discipline and need for autonomy as adolescence is a developmentally challenging period. The current paper reviews twofold objectives: first is to comprehend the relationship between psychosocial factors, Psychoeducation and type 1 diabetes. Second is to uncover the implications of Psychoeducation in health care practice. A review of 40 studies from 1991 to 2014 was carried out to understand the role of Psychoeducation in type 1 diabetes. The studies reviewed indicates a positive association between Psychoeducation, quality of life, reduction in disturbed eating pattern and management of their health condition.

Keywords: Type 1 Diabetes, Psychoeducation

Type 1 diabetes mellitus is a chronic medical condition that occurs when pancreas produces little or no insulin, requiring diligent blood sugar monitoring, lifestyle modifications, treatment and prevention of complications related to the disorder through introduction of Psychoeducation. Childhood is the usual age of onset but an individual can develop it at any age. The only treatment available at present is insulin which has to be injected in the body through injections, pump or pen.

Management of diabetes is a difficulty for adolescents since they are entangles in issues of exerting independence, developing self-concept, onset of puberty as puberty can be the causal factor for resistance of insulin (Anderson, Ho, Bracket, Finkelstein \& Laffel, 1997). As diabetic

\footnotetext{
${ }^{1}$ Research Fellow, Dept. Of Psychology, Jain University, Bangalore, Karnataka, India

${ }^{2}$ Research Guide, Jain University \& Assistant Professor, Dept. Of Psychology, Acharya Group of Institutions,

Bangalore, Karnataka, India

*Responding Author

(C) 2016 I S Malhotra, S Antony; licensee IJIP. This is an Open Access Research distributed under the terms of the Creative Commons Attribution License (http://creativecommons.org/licenses/by/2.0), which permits unrestricted use, distribution, and reproduction in any Medium, provided the original work is properly cited.
} 


\section{Role of Psychoeducation on Self- Management of Type 1 Diabetes in Adolescents - A Review}

adolescents require consistent monitoring, it increases the intensity of intrusiveness of the caregiver (Weinger, O’Donnel \& Ritholz, 2001).adolescents may see their parents as limitations on food as efforts to control them and may regard the need to monitor diet and be conscientious about injections as rules and regulations imposed from outside which can lead to family conflict (Wysocki, 1993). Moreover, within the adolescent peer culture, those who are different are often stigmatized. Thus, the adolescent having diabetes may neglect appropriate care to avoid rejection. Emotionally stable and assiduous adolescents are more likely to follow the complex regimen requires by the demanding health condition compared to thosw who do not have these qualities (Skinner, Hampson \& Fife-Shaw, 2002).

Children and adolescents are most of the time in school, involves in extra curricular activities or with friends wherein the monitoring of adults or peers is not always a constant process and neither do they prefer it due to the need to become independent which is a major characteristic of adolescence. Thus, they need to take the route of self-management by becoming aware of the myths and facts allied with diabetes and learn how to manage their condition on a routinely basis, how to handle emergency situations and how to lead an active life by keeping prospective complications at bay. Psychoeducation is an effective way through which knowledge and independence derived from knowledge can be wielded along with fulfilling the responsibility of self-management.

Psychoeducation is an effective integration of educational and psychotherapeutic interventions. It provides psychological support along with providing requires medical information. The strength of the Psychoeducation lies in the ability to focus on the present and on the drive of the receiver. Thus, Psychoeducation induces confidence of control of the disease and how it can be sustained with continuous management (Snoek et al., 1999). The aim of review is to explore the role of Psychoeducation in adherence of regimen, impact of psychosocial factors, optimal management of blood glucose level, mental health issues such as anxiety and depression and coping with the disorder.

\section{OUTCOME OF PSYCHOEDUCATION IN DIABETES}

Literatures concerning the current topic were reviewed for the current paper. $15 \%$ of the studies on Psychoeducation that have yielded remarkably significant value have been listed in the table below. The research design of these studies are randomly controlled design and assessments were done after 3,6,12,18 months interval: altering for all six mentioned studies. For these six studies, Psychoeducation program included educational awareness along with psychotherapy namely Cognitive Behaviour Therapy, Rational Emotive Therapy, problem solving and educational manager included internet programs designed for executive purpose. In all the research studies, Psychoeducation is based on the crux of making adolescents independent to manage their health condition. Also, therapeutic interventions included in psychotherapy have yielded positive results. 
In majority of the research studies retrieved, the focus is centred around cognitions, thoughts and problem solving but emphasis on emotional regulation is not laid. Into the bargain, the variables cyclically researched and assessed embrace coping, quality of life, diabetes distress, clinical correlates of diabetes, self-efficacy, family conflict, and regimen adherence. Thus, the variables researched reveal that cognition precedes emotions. Through reflection, the variables that can be hoisted to endow the adolescent with self-management skills can include peer acceptance/rejection/respect/adjustment; emotional support received from sibling/family/friends, motivation, emotional regulation, institutional responsibility corporal characteristics such as obesity, medical complications and choice of careers.

\begin{tabular}{|c|c|c|c|}
\hline Authors & $\begin{array}{ll}\text { Year } & \text { of } \\
\text { Publishing }\end{array}$ & Significance Level & Factors \\
\hline 1. BM Sworen et al., & 2003 & $\begin{array}{l}\text { Annual rate of } \\
\text { severe } \\
\text { hypoglycaemia } \\
\text { requiring parental } \\
\text { therapy in the group } \\
\text { receiving } \\
\text { psychoeducation } \\
\mathrm{p}=0.01 \text { hospital } \\
\text { Annual rate was } \\
\text { admission rate } \\
\text { lower in the control } \\
\text { group p=0.04 } \\
\text { Annual rate of } \\
\text { emergency } \\
\text { department visits in } \\
\text { the control group } \\
\text { was lower p=0.004 }\end{array}$ & $\begin{array}{l}\text { Hypoglycaemia } \\
\text { Hospital admission } \\
\text { Emergency } \\
\text { department visits }\end{array}$ \\
\hline 2. Grey Margaret et al., & 2013 & 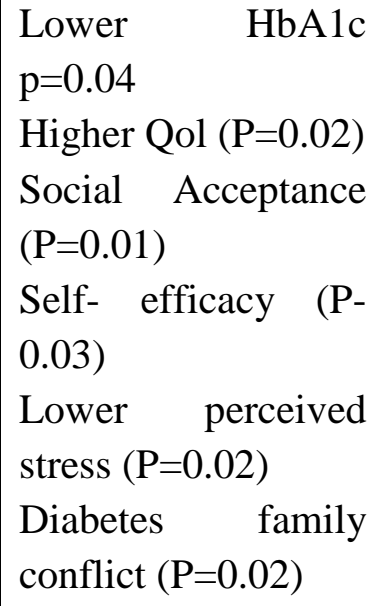 & $\begin{array}{l}\text { HbA1c } \\
\text { Quality of Life } \\
\text { Coping } \\
\text { Social-competence } \\
\text { Self-management } \\
\text { Family conflict }\end{array}$ \\
\hline
\end{tabular}

(c) The International Journal of Indian Psychology, ISSN 2348-5396 (e)| ISSN: 2349-3429 (p) | 185 
Role of Psychoeducation on Self- Management of Type 1 Diabetes in Adolescents - A Review

\begin{tabular}{|c|c|c|c|}
\hline Authors & $\begin{array}{l}\text { Year of } \\
\text { Publishing }\end{array}$ & Significance Level & Factors \\
\hline $\begin{array}{ll}\text { 3. } & \text { Mulvaney A. } \\
\text { Shelgauh et al., } & \end{array}$ & 2009 & $\begin{array}{l}\text { Self-management } \\
(\mathrm{P}=0.02) \\
\text { Improvement in } \\
\text { problem solving } \\
(\mathrm{P}=0.23) \\
\text { Consistency } \\
\mathrm{A} 1 \mathrm{C}(\mathrm{P}=0.27)\end{array}$ & $\begin{array}{l}\text { Self-management } \\
\text { Problem-solving } \\
\text { HbA1c }\end{array}$ \\
\hline $\begin{array}{l}\text { 4. EC Morelnad and } \\
\text { associates }\end{array}$ & 2004 & $\begin{array}{l}\text { Daily BGM } \\
\text { frequency }(p=0.02) \\
\text { Family involvement } \\
\text { for diabetes } \\
\text { management } \\
(p<0.001)\end{array}$ & $\begin{array}{l}\text { Glycemic control } \\
\text { Family involvement } \\
\text { Adherence to BGM }\end{array}$ \\
\hline $\begin{array}{l}\text { 5. Snoek J.Frank and } \\
\text { associates }\end{array}$ & 1999 & $\begin{array}{l}\text { Average drop in } \\
\text { worst control of } \\
\text { HbA1c }=>0.5 \% \\
\text { Improved positive } \\
\text { well-being } \mathrm{P}<0.5 \% \\
\text { Decreased diabetes } \\
\text { distress } \mathrm{P}<0.5\end{array}$ & $\begin{array}{l}\text { HbA1c } \\
\text { Well -being } \\
\text { Diabetes distress }\end{array}$ \\
\hline 6. Grey Margaret et al., & 2009 & QOL impact $\mathrm{p}=0.02$ & $\begin{array}{l}\text { Quality of life } \\
\text { Metabolic control } \\
\text { Coping } \\
\text { Self-efficacy } \\
\text { Family functioning }\end{array}$ \\
\hline 7. Zoysa et al., & 2014 & $\begin{array}{l}\text { Hypoglycemia } \\
\text { awareness improved } \\
(\mathrm{P}<0.001)\end{array}$ & Hypoglycaemia \\
\hline
\end{tabular}

\section{STUDY CHARACTERISTICS}

A. Psychological morbidities in diabetic adolescents

Depression and anxiety disorders are most common diagnoses among people with diabetes and these conditions occur more often in patients than in the general population (Hood et al., 2006). Psychological feature such as diabetes and anxiety can complicate the management of diabetes. In a primary care population, major depression in diabetics was mainly associated with behaviours that had been initiated by the patient such as exercise, managing medication, diet but have now become difficult to maintain (Lin et al., 2004). Prevalence of depression in diabetic population is higher as compared to non-diabetic population. This has been demonstrated by

(C) The International Journal of Indian Psychology, ISSN 2348-5396 (e) | ISSN: 2349-3429 (p) | 186 


\section{Role of Psychoeducation on Self- Management of Type 1 Diabetes in Adolescents - A Review}

Goldney and his associates in a study conducted in 2004, that prevalence in diabetic population was $24 \%$ comparative with non-diabetic population of $17 \%$. In another review article by Anderson and his associates (2001) and Malhotra \& Reddy (2013), the prevalence of depression is present in clinical samples to a greater degree as compared with non-clinical samples.

Clinically diagnosable eating disorders also appear to be more prevalent among people with diabetes than in general population; this association is especially strong in young women and it increases the risk of developing diabetes complications. Depression, anxiety and eating disorders can all be treated effectively but they tend to recur and may require repeated treatment. Eating disorder is correlated to irregular glycemic control, retinopathy and divergence between parent and child on the issue of food can hinder diabetes management (Lustman \& Harris, 1998).

Quality of life increases with administration of skills program (Grey, Boland, Davidson, Li \& Tamborlane, 2000). Grey and her colleagues reported that adolescents who practiced intensive diabetes management and received coping skill training had lower A1c levels, had more confidence in their ability to manage their diabetes and reported less impact of diabetes on their quality of life than adolescents who practiced intensive management but did not receive coping skill training.

In a study conducted by Grey et al., 2013, with 320 youth aged between 11-14 years, Psychoeducation was delivered in the form of two internet programs and after time span of 18 months, youth who had completed both the programs reported higher quality of life, lower perceived stress, lower diabetes related family conflict, increased social acceptance and selfefficacy compared to those who had completed only one program. Quality of life is adversely impacted by diabetes (Brown et al., 2004; Lustman et al., 2000; Gavard JA et al., 1993; Ciechanowski PS et al., 2000 ).

\section{B. Non adherence in diabetes care}

Non adherence can be notices in the structure of somber psychological problems such as eating disorder, anxiety, depression which can be further treated by psychotherapy (Lustman \& Harris, 1998; MG Pereira, Cross-Berg, P Almeida, JC Machado, 2008). Adherence to managing diabetes is independent of gender (Pattino AM, Sanchez J, Edison M, Delamater AM, 2005; Naar-King S et al., 2006). Enhancement in adherence is optimistically correlated with variables such as coping, self-efficacy, family functioning and psychosocial modification metabolic organization (Graue, Wentzel-Larsen, Bru, Hanested \& Sovik, 2004; Grey, Lipman, Cameron \& Thurber, 1997; Giva, Myers \& Newman, 2000).

\section{Blood glucose}

The optimal management of blood glucose is related to diabetes explicit family disagreement. Disappointment of not achieving most favourable management can lead to conflict and the 


\section{Role of Psychoeducation on Self- Management of Type 1 Diabetes in Adolescents - A Review}

family's concern only with the blood glucose level increases the patient's anxiety (Williams, Laffell, Hood, 2009; Anderson et al, 2002; Hood, Butler, Anderson, Lafell, 2007; Lewin et al., 2006; Herge et al., 2012).

\section{Coping with diabetes related distress}

Grey and her colleagues reported that adolescents who practiced intensive diabetes management and received coping skills training had lower A1c levels, had more confidence in their ability to manage their diabetes and reported less impact of diabetes on their quality of life than adolescents who practiced intensive management but did not receive coping skill training. Wysocki and colleagues reported mixed results for families of adolescents who participated in a trial of behavioural family systems therapy (BFST).participants in this group had better parentadolescent relationships but no improvement in adjustment to diabetes or glycemic control, compared with those receiving standard treatment.

In another controlled trail, Anderson and her colleagues provided separate group sessions for adolescents and their parents as a supplement to regular diabetes clinic visits. The goal of the sessions was to increase skill in using self-monitored blood glucose data for regimen adjustments. The goal of the parents session was to develop strategies for negotiating appropriate levels of parental involvement in the adolescents diabetes care. Eighteen months after completion of the 12 session group intervention, adolescents in the treatment group had significantly lower A1c levels and reported significant more use of SMBG data for selected regimen adjustments than adolescents in the control group. In some settings, coping skill training is incorporated into broader programmes of self-management education. In fact, the American Diabetes Association has stated that "Diabetes specific coping skills training (CST) is designed to help patients overcome barriers to the successful application of new knowledge and skills. This intervention is designed to improve patient's emotional well-being, diabetes self-care and long term blood glucose control. The CST approach used in this program is a psychoeducational group intervention that addresses attitudes and behaviours that underlie individual patterns of self-care”. Thus, this leads to positive outcome (Davidson, Boland \& Grey, 1997).

In a group setting, individuals begin the process of identifying their own personal regimen barriers or 'sticking points'. Patients are encouraged to identify sticking points as specifically as possible; the more expressly the sticking points are defined, the easier it is to resolve. Once a personal issue has been identified, patients help each other develop strategies for dealing with these issues, focusing on the approaches that have been successful in the past. A key goal of this process is to help patients recognize that certain thoughts or attitudes trigger distress and nonconstructive behaviour, while erstwhile thoughts and outlook trigger a process that leads to better outcomes. In a study conducted by Whittemore $\mathrm{R}$ and his associates, diabetic adolescents having 


\section{Role of Psychoeducation on Self- Management of Type 1 Diabetes in Adolescents - A Review}

lower glycosylated haemoglobin and higher depressive symptoms are more likely to participate and benefit from the Psychoeducation program.

\section{IMPLICATIONS}

Though Psychoeducation is an effectual way to improve mental health by being educated about the disorder and receiving psychotherapy, there is a need to address other aspects associated with it rather than the cognitive component only; varied aspects include emotional adjustment, situational adjustments in the form of life events that can be overpowering, choice of professional careers. In addition, Psychoeducation can also be given to friends, peers, family, colleagues of the person affected with diabetes. Through this awareness among the public about health conditions will improve along with adjustment with the afflicted and for the afflicted. Hence, the requirement of a mental health expert for the purpose of managing chronic illness has developed.

\section{Acknowledgments}

The author appreciates all those who participated in the study and helped to facilitate the research process.

\section{Conflict of Interests}

The author declared no conflict of interests.

\section{REFERENCES}

Anderson BJ, Brackett J, Ho J, Laffel LM. 1999. An office-based intervention to maintain parent-adolescent teamwork in diabetes management. Impact on parent involvement, family conflict, and subsequent glycemic control. Diabetes Care. 22:713-721.

Anderson BJ, Vangsness L, Connell A, Butler D, Goebel-Fabbri A, Laffel LM. 2002. Family conflict, adherence, and glycaemic control in youth with short duration Type 1 diabetes. Diabet Med. 19: 635-642.

Anderson RJ, Freedland KE, Clouse RE, Lustman PJ. 2001. The prevalence of comorbid conditions in adults with diabetes:a meta-analysis. Diabetes Care 24:1069-1078.

BM Sworen, D Butler, B-S Levine. 2003. Reducing acute adverse outcomes in youth with type 1 diabetes: a randomized controlled trial. Pediatrics. 112:914-22

Brown GC, Brown MM, Sharma S, Brown H, Gosum M, Denton P. 2004. Quality of life associated with diabetes mellitus in an adult population. J Diabetes Complications 14:1824, 2000

Ciechanowski PS, Katon WJ, Russo JE. 2000. Depression and diabetes: impact of depressive symptoms on adherence, function and costs. Arch Intern Med 160:3278-3285.

Davidson M, Boland EA, Grey M. Teaching teens to cope. 1997. Coping skills training for adolescents with insulin-dependent diabetes mellitus. Journal of the Society of Pediatric Nurses. 2:65-72. 


\section{Role of Psychoeducation on Self- Management of Type 1 Diabetes in Adolescents - A Review}

EC Moreland, A Tovar, JB Zuehlke, DA Butler, K Milaszewski, LM Laffel. 2004. The impact of physiological, therapeutic and psychological variables on glycemic control in youth with type 1 diabetes mellitus. Journal of Pediatric Endocrinology Metabolism. 17(11),1553-44.

Finkelstein EA, Bray JW, Chen H, Larson MJ, Miller K,Tompkins C, Keme A, Mandersheid R. 2003. Prevalence and costs of major depression among elderly claimants with diabetes. Diabetes Care 26:415-420.

Gavard JA, Lustman PJ, Clouse RE. 1993. Prevalence of depression in adults with diabetes: an epidemiological evaluation. Diabetes Care16:1167-1178

Goldney D. Robert, Phillips J. Pat, Fisher J. Laura, Wilson H. David. 2004. Diabetes, Depression and Quality of Life, Diabetes Care, doi: 10.2337/diacare 27.5.1066 vol 27 no.5 1066-1070

Graue M, Wentzel-Larsen T, Bru E, Hanestad BR, Sovik O. 2004. The coping styles of adolescents with type 1 diabetes are associated with degree of metabolic control. Diabetes Care. 27:1313-1317.

Grey M, Boland EA, Davidson M, Li J, Tamborlane WV. 2000. Coping skills training for youth with diabetes mellitus has long-lasting effects on metabolic control and quality of life. Journal of Pediatrics;137:107-113

Grey M, Lipman T, Cameron ME, Thurber FW. 1997. Coping behaviors at diagnosis and in adjustment one year later in children with diabetes. Nursing Research.;46:312-31

Grey Margaret, Whittemore Robin, Jaser Sarah, Ambrosino Jodie, Lindemann Evie, Liberti Lauren, Northrup Veronika, Dzuria James. 2009. Effects of Coping Skills Training in School- age Children with Type 1 Diabetes, Res Nurs Health. 32(4): 405-418. doi:10.1002/nur.20336

Grey Margaret, Whittemore Robin, Jeon Sangchoon, Murphy Kathryn, Faulkner S.Melissa, Delamater Alan. 2013. Internet Psycho-Education Programs Outcomes in for Youth with Type 1 Diabetes, Diabetes Care. 36(9): 2475-2482, doi: 10.2337/dc12-2199

Griva K, Myers LB, Newman S. 2000. Illness perceptions and self efficacy beliefs in adolescents and young adults with insulin dependent diabetes mellitus. Psychology \& Health. 15:733-750.

H.B Elizabeth, Korff Von Michael, Rutter Carolyn, Simon E Greg, Oliver Malia, Bush Terry, Ludman L.Evette, Katon Wayne, Ciechanowski Paul, Young Bessie, 2004,Relationship of Depression and Diabetes Self-Care, Medication Adherence and Preventive Care, Diabetes Care, doi: 10.2337/diacare.27.9.2154 vol.27 no.9 2154-2160

Hanna M. Kathleen, RN, Guthrie W.Diana, 2003, Parental Involvement in Adolescent's Diabetes Management, Diabetes Spectrum July, vol.16 no.3 184-187, doi:10.2337/diaspect 16.3.184

Harris A Michael, Lustman J Patrick. 1998. The Psychologist in Diabetes Care, Clinical Diabetes, VOL 16 NO. 2

Herge M.Whitney, Streisand Randi, Chen Rusan, Holmes Clarissa, Kumar Anil, Mackey Race Eleanor. 2012. Family and Youth Factors Associated With Health Outcomes in Yoth with Type 1 Diabetics. Journal of Pediatric Psychology 37(9) pp. 980-989, 


\section{Role of Psychoeducation on Self- Management of Type 1 Diabetes in Adolescents - A Review}

doi:10.1093/jpepsy/jss067

Hood KK, Butler DA, Anderson BJ, Laffel LM. 2007. Updated and revised Diabetes Family Conflict Scale. Diabetes Care; 30:1764-1769.

Hood KK, Huestis S, Maher A, Butler D, Volkening L, Laffel LM. 2006. Depressive symptoms in children and adolescents with type 1 diabetes: Association with diabetes-specific characteristics. Diabetes Care. 29:1389-1391.

Lewin AB, Heidgerken AD, Geffken GR, Williams LB, Storch EA, Gelfand KM. 2006. The relation between family factors and metabolic control: the role of diabetes adherence. Journal of Pediatric Psychology; 31: 174-183.

Lustman PJ, Anderson RJ, Freedland KE, deGroot M, Carney RM, Clouse RE. 2000. Depression and poor glycaemic control: a meta-analytic review of the literature. Diabetes Care 23:934-942

Lustman PJ, Clouse RE, Alrakawi A, Rubin EH, Gelenberg AJ. 1997. Treatment of major depression in adults with diabetes: a primary care perspective. Clinical Diabetes 16:122-26

Malhotra Sanjana, K.Reddy Jayashankar. 2013. Psychological Distress in Diabetes: A Critical Review. International Journal of Recent Scientific Research, Vol 4, Issue, 9, pp.1381-1384

MG Pereira, Cross-Berg, P Almeida, JC Machado. 2008. Impact of family environment and support on adherence, metabolic control and quality of life in adolescents with diabetes, International Journal of Behavior Medicine.15(3):187-93.

Doi:10.1080/10705500802222436.

Mulvaney A.Shelgah, Rothman L.Russell, Wallston, A.Kenneth, Lybarger Cindy, Dietrich S.Mary. 2010. An Internet-Based Program to Improve Self-Management in Adolescents With Type 1 Diabetes, Diabetes Care. 33(3): 602-604. Doi:10.2337/dc09-1881

Naar-King S, Idalski A, Ellis D. 2006.Gender differences in adherence and metabolic control in urban youth with poorly controlled type 1 diabetes: the mediating role of mental health symptoms. Journal of Pediatric Psychology. 31(8):793-802.

Rydall AC, Rodin GM, Olmsted MP, Devenyi RG, Daneman D. 1997. Disordered eating behavior and microvascular complications in young women with insulin-dependent diabetes mellitus. N Engl J Med 336:1849-54

Schreiner Barb, Brow Shannon, Phillips Monica, 2000, Management strategies for the adolescent lifestyle, diabetes spectrum, vol 13, no 2.

Skinner, Hampson, \& Fife-Shaw, Personality, personal model beliefs and self-care in adolescents and young adults with Type 1 diabetes, Health Psychol. 2002 Jan;21(1):61-70.

Snoek J.Frank, van der Ven C.W. Nicole, Lubach Caroline, Cognitive Behavioral Group Training for Poorly Controlled Type 1 Diabetes: A Psychoeducational Approach. Diabetes Spectrum, Volume 12 Number 3, 1999, Page 47

Speers MA, Turk DC: Diabetes self-care: knowledge, beliefs, motivation and action. Pat Couns Health Educ 4:144-214, 1982

Weinger K, O'Donnell KA, Ritholz MD. Adolescent views of diabetes-related parent conflict and support: a focus groupanalysis. Journal of Adolescent Health. 2001;29:330-336

(C) The International Journal of Indian Psychology, ISSN 2348-5396 (e)| ISSN: 2349-3429 (p) | 191 


\section{Role of Psychoeducation on Self- Management of Type 1 Diabetes in Adolescents - A Review}

Whittemore Robin, , Jaser S S arah, Faulkner S M Elissa, Murphy Kathryn, Delamater, Grey Margaret. 2013. Type 1 Diabetes eHealth Psychoeducation: Youth Recruitment, Participation and Satification, L Med Internet Res; doi: 10.2196/jmir.2170.

Williams L.B, Laffel L.M.B, Hood K.K. 2009. Diabetes-specific family conflict and psychological distress in paediatric Type 1 diabetes. Diabetic Medicine, Vol 26(9), 908-91.

Wysocki T. 1993. Associations among teen-parent relationships metabolic control, and adjustment to diabetes in adolescents. J Pediatric Psychology 18:441-52.

Wysocki T. 1993. Associations among teen-parent relationships, metabolic control, and adjustment to diabetes in adolescents. Journal of Pediatric Psychology. 18:441- 452.

Zoysa de Nicole, Rogers Helen, Stadler Marietta, Gianfrancesco Carla, Beveridge Susan, Britneff Emma, Choudhary Pratik, Elliot Jackie, Heller Simon, Amiel, A. Stephanie. 2014. A psychoeducational program to restore hypoglycemia awareness: the DAFNEHART pilot study. Diabetes Care, vol 37 (3), 863-866; doi: 10.2337

How to cite this article: S Malhotra, S Antony (2016), Role of Psychoeducation on SelfManagement of Type 1 Diabetes in Adolescents - A Review, International Journal of Indian Psychology, Volume 3, Issue 4, No. 56, ISSN 2348-5396 (e), ISSN: 2349-3429 (p), DIP: 18.01.019/20160304, ISBN: 978-1-365-23992-2 